University of Nebraska - Lincoln

DigitalCommons@University of Nebraska - Lincoln

2-3-1983

\title{
Climate Model for Winter Wheat Yield Simulation
}

\author{
Kenneth G. Hubbard \\ University of Nebraska-Lincoln, khubbard1@unl.edu \\ R.J. Hanks \\ Utah State University
}

Follow this and additional works at: https://digitalcommons.unl.edu/natrespapers

Part of the Natural Resources and Conservation Commons, Natural Resources Management and Policy Commons, and the Other Environmental Sciences Commons

Hubbard, Kenneth G. and Hanks, R.J., "Climate Model for Winter Wheat Yield Simulation" (1983). Papers in Natural Resources. 1102.

https://digitalcommons.unl.edu/natrespapers/1102

This Article is brought to you for free and open access by the Natural Resources, School of at DigitalCommons@University of Nebraska - Lincoln. It has been accepted for inclusion in Papers in Natural Resources by an authorized administrator of DigitalCommons@University of Nebraska - Lincoln. 


\title{
Climate Model for Winter Wheat Yield Simulation
}

\author{
KENNETH G. HUBBARD' \\ Center for Agricultural Meteorology and Climatology, University of Nebraska, Lincoln 68583
}

\author{
R. J. HANKS
}

Department of Soil Science and Biometeorology, Utah State University, Logan 84321

4 September 1982 and 3 February 1983

\begin{abstract}
Winter wheat yields were simulated by a model requiring climatic data as input for estimating crop evapotranspiration and phenological development. An assumed relationship between the winter wheat yields and the amount and timing of crop water use was optimized to simulate yields for two case studies: a single season, irrigated wheat study and a multi-year, dryland wheat study. The model explained more than $90 \%$ of the variance of wheat yields in the irrigated study where total irrigation amounts varied between 0 and $55 \mathrm{~cm}$. About $40 \%$ of the variance was explained for annual yields from a 21 -year, dryland winter wheat study.
\end{abstract}

\section{Introduction}

Agricultural management and planning phases in the farming and livestock industries can benefit from an accurate prediction of plant growth and development. For example, minimum crop irrigation based upon knowledge of resultant plant growth and development could both preserve optimum yields and yet use less irrigation water. For an irrigation system with pump delivery, the benefits would be threefold: optimum yields, water conservation, and energy savings. Another beneficial application of climate models that estimate yield would be the ranking of possible real estate investments according to the average simulated yield as predicted from existing climate data. Yet another possible use of yield simulators is the projection of foreign and domestic grain production for the benefit of grain farmers and livestock producers as well, since they feed grain to cattle and hogs. Based on foreign and domestic projections, a strategy for marketing and transportation could be formulated long in advance of the harvest season. The impact of climatic change on world agricultural production could also be examined if an accurate plant growth simulation was available.

The accuracy necessary to totally achieve the goals outlined above is not now attainable, but the fact that such benefits may be possible provides justification for developing models that estimate crop yield over a wide range of environmental conditions. An un-

\footnotetext{
' Formerly Assistant State Climatologist, Utah Department of Agriculture.
}

derstanding of the environmental sensitivities that crops exhibit is a prerequisite to accurate prediction of crop growth. The objective of this study was to develop a model that simulates winter wheat yield in a wide range of conditions. The details of the model developed will be outlined in the next section.

\section{Model development}

The basis for the climate model of wheat yield simulation is presented below. For more detail see Hubbard (1981).

\section{a. Crop yield prediction}

One response of crop production to climatic influences has been suggested (deWit, 1958):

$$
P_{c}=\frac{f T_{r}}{E_{t p}},
$$

where $P_{c}$ is the above ground dry matter produced, $E_{t p}$ the average potential evapotranspiration for the environment in which the crop was grown, $T$, the actual transpiration of the crop expressed as an equivalent water depth and $f$ is a crop factor to be determined empirically. This equation was proposed as applying in the regions of the world with limited water and abundant radiation. Tanner (personal communication, 1982) has suggested that this equation would have wide applicability if $E_{t p}$ was replaced by a vapor pressure deficit term.

A variation of (1) was suggested earlier for use in prediction of plant yields as influenced by water use (Hanks, 1974): 


$$
\frac{Y}{Y_{p}}=\frac{T_{r}}{T_{r p}}
$$

where the yield $Y$ is assumed to depend on transpiration $T_{r}$, the potential transpiration $T_{r p}$ and the potential yield for a particular crop $Y_{p}$.

Nairize and Rydzewski (1977) showed that the yield of many crops is a weighted function of the water available for growth and development during the growing season:

$$
\frac{Y}{Y_{p}}=\frac{\sum_{i=1}^{k} \lambda_{i} T_{r i}}{\sum_{i=1}^{k} \lambda_{i} T_{r p i}}
$$

where $\lambda_{i}$ is the sensitivity index of the crop to water stress during the $i$ th stage of development and $k$ the number of crop growth stages.

In the present model (3) was used in the form

$$
Y=a+b \frac{\sum_{i=1}^{k} \lambda_{i} T_{r i}}{\sum_{i=1}^{k} \lambda_{i} T_{r p i}} .
$$

The variables appearing in the rhs of (4) are output from the model with the exception of $a$ and $b$ which were estimated with linear regression between actual yields and model outputs. Derivation of (4) was accomplished by assuming that the lhs of (3) could be approximated by

$$
\frac{Y}{Y_{p}}=\frac{Y-a}{Y_{p}-a} .
$$

By substituting (5) into (3) and expanding we obtain (4) after some simplification $\left(Y_{p}=a+b\right)$. This treatment assumes that $Y_{p}$ is a constant for a given location.

An example of the variation of $\lambda$ through the growing season is shown in Fig. 1 for spring wheat. A curve of this form was assumed for winter wheat because all of the grains examined by Nairize and Rydzewski (1977) showed a higher sensitivity at the middle of the growing season.

\section{b. Crop growth stage and canopy temperatures}

Pinpointing the crop growth stage requires detailed observations. Growing degree day accumulations and thermal units have, however, been used to predict phenological progress (e.g., Nuttonson, 1953; Heuer et al., 1978; Hodges and Doraiswamy, 1979). An experimentally determined temperature response for wheat $\mathrm{CO}_{2}$ assimilation rate (Jolliffe and Tregunna, 1968) was used to estimate the relative growth rate (Fig. 2). The accumulation of relative growth rate $R G R$ units as determined from this relationship and

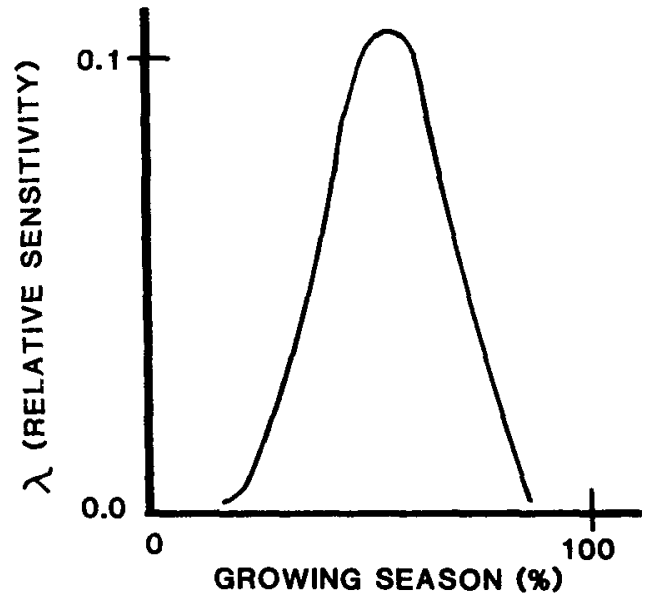

FIG. 1. An example of a crop weighting function-spring wheat (Nairize and Rydzewski, 1977).

daily temperatures were used to estimate the crop progress. This accumulation during the growing season was used to estimate growth $G$ or phenological progress according to

$$
G=\sum R G R(\theta)
$$

where $R G R$ is defined by Fig. 2 , and $\theta$ is temperature.

In the growth chamber (Jolliffe and Tregunna, 1968) $R G R$ can be determined as a function of the temperature of wheat plants. In the real environment the most readily available temperature measurements are from weather instrument shelters. Recent studies (Ehrler et al., 1978) have examined temperature differences between the canopy and the air above. The difference between the canopy and air temperature was positive when lower plant water potential was observed. This is in part due to the closure of stomatal openings and subsequent restriction of transpiration so that incoming energy is not used in transpiration but increases the sensible heat load and thus raises the temperature. The difference between canopy and air temperature was also observed to undergo a diurnal oscillation.

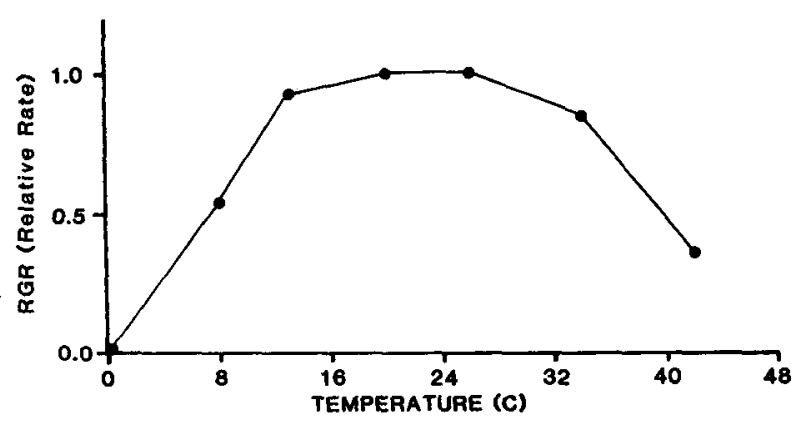

FIG. 2. The relative growth rate of winter wheat (ratio of actual to maximum $\mathrm{CO}_{2}$ assimilation rate) as a function of temperature. 
Since the crop is experiencing temperature measured at the crop canopy rather than at the weather instrument shelter, an adjustment was made to reported climatic temperatures. The temperature difference between canopy and air is empirically derived for this model in the following fashion:

$$
\Delta \theta=\frac{\left(1-T_{r}\right)}{T_{r p}} \Delta \theta_{U}+\frac{\left(T_{r}\right)}{T_{r p}} \Delta \theta_{L},
$$

where $\Delta \theta_{U}$ is a time dependent upper limit on temperature difference for a crop undergoing drought stress, and $\Delta \theta_{L}$ is a time dependent lower limit on temperature difference for a well-watered crop. A diurnal specification of $\Delta \theta_{L}$ and $\Delta \theta_{U}$ was employed (Hubbard, 1981). Thus, air temperature can be used as a basis for estimating the crop canopy temperature:

$$
\theta=\theta_{\text {air }}+\Delta \theta \text {. }
$$

The use of this temperature adjustment does cause a feedback between the estimated soil moisture status and the calculated phenological progress of the crop. Low soil moisture in the model causes reduced transpiration which in turn leads to warmer canopy temperatures and therefore a different thermal environment than otherwise.

It should be noted that the inclusion of this temperature adjustment can hasten or slow the development of the simulated wheat crop and together with the $\lambda$ coefficient of (4) gives and interaction between water stress, temperature (air and canopy), phenology, and yield. An earlier study (Idso et al., 1980) showed that canopy temperature in the form of "stress-degree days" is highly correlated to crop yield.

Hastened development of wheat plants under mild water stress has been demonstrated (Angus and Moncur, 1977) although with severe water stress the wheat plants were observed to actually delay development. An examination of Fig. 2 reveals that $R G R$ in the current model can be slowed when canopy temperatures rise above $\sim 25^{\circ} \mathrm{C}$. The use of $\Delta \theta$ can also hasten model crop development if water stress causes an increase of canopy temperature over any air temperature below $\sim 20^{\circ} \mathrm{C}$. The model testing concentrated on yield simulation, but it would be interesting to see if the findings of Angus and Moncur (1977) could be simulated with the present model.

In studies of the need for chilling or vernalization of wheat (required period of exposure to low temperature) it has been shown (Chujo, 1966; Trione and Metzger, 1970) that maximum vernalization rates occur at $4-8^{\circ} \mathrm{C}$ with little effect below 1 or above $12^{\circ} \mathrm{C}$. The current model uses the relationship

$$
v\left(\theta_{\text {air }}\right)=K_{v}^{3}\left[\left(\theta_{\text {air }}-\theta_{0}\right)^{2}+K_{v}^{2}\right]^{-1}
$$

to calculate the relative vernalization rate at any temperature. The optimum temperature $\theta_{0}$ was taken as $5^{\circ} \mathrm{C}$ and $K_{v}$ was set equal to 1 . This value of $K_{v}$ gives a vernalization rate at 0 and $10^{\circ} \mathrm{C}$ of $1 / 26$ th that at $5^{\circ} \mathrm{C}$. Vernalization accumulations were started in the fall and continued through spring

$$
V=\sum v\left(\theta_{\text {air }}\right),
$$

where air temperature was assumed to vary linearly between daily maximum and minimum readings.

The phenological time clock was then modified according to the degree of vernalization $D$

$$
\begin{array}{ll}
D=D_{v}, & V \geqslant 400, \\
D=1+\left(D_{v}-1\right)(V-150) / 250, & V<400 .
\end{array}
$$

Above a threshold of vernalization (400) the phenological development was not changed. The phenological development required a larger accumulation of $R G R$, however, to reach the same relative stage of maturity when a lower degree of vernalization was present. This procedure was developed by examining the climatology of vernalization and selecting a reasonable threshold for the area. The constant $D_{v}$ was determined from sensitivity analysis of the Nephi data $\left(D_{v}=0.7\right)$.

\section{c. Crop water use}

The stored soil moisture $S$ determines how much water is available at any time for evapotranspiration $E T$. This methodology is widely used in modeling crop yields (Baier, 1981). Changes in soil moisture status are determined from a mass balance equation:

$$
\Delta S=p+I-r_{0}-E T,
$$

where $p$ is precipitation, $I$ irrigation, and $r_{0}$ is surface runoff. Runoff was estimated as all moisture above a certain threshold, and sensitivity analysis indicated a precipitation threshold of $2.3 \mathrm{~cm}$. Other terms may be required in soils where either drainage below the root zone or a shallow water table exist. The two components of evapotranspiration are the crop water use (transpiration) and the evaporation from the soil surface $E$ :

$$
E T=T_{r}+E .
$$

Transpiration is difficult to measure but can be estimated by considering the physical features of the plant-soil system. A crop extracts less soil moisture as the soil becomes increasingly drier. If dryness continues for a considerable time, the crop will not be able to remove further water from the soil. The water to which a plant does have access in a soil can be determined experimentally by moistening the soil in which the plants are growing to the point when "field capacity" is reached. The transpiration from the plants is then accumulated until plant water extraction ceases or the wilting point is reached. The max- 
imum amount of water (expressed volumetrically) available to the particular crop in this soil is then:

$$
A W=\Delta S \text { (Field capacity }- \text { Wilting point }) / d \text {, }
$$

where $d$ is depth of the soil.

The fraction of soil moisture remaining in the profile at any time is then

$$
F=\frac{S}{d A W} .
$$

Crop water use can be assumed to proceed at the potential transpiration rate when the soil moisture fraction remains between a critical value $F_{k}$ and unity, i.e.,

$$
T_{r}=T_{r p}
$$

When $F$ falls below $F_{k}\left(F_{k}=0.5\right)$, the transpiration rate falls below the potential transpiration rate accordingly. This can be expressed as:

$$
T_{r}=\left(F / F_{k}\right) T_{r p}
$$

In this model, potential transpiration rates were estimated from procedures outlined by-Childs and Hanks (1975) or Retta and Hanks (1980) which involve knowing crop coefficients and potential evapotranspiration. Potential evapotranspiration was calculated from climatic data using the modified Blaney-Criddle method (Doorenbos and Pruitt, 1977).

The combination of (4) and (6) through (17) formed the model used in simulating grain yield for winter wheat crops grown under both dryland and irrigation.

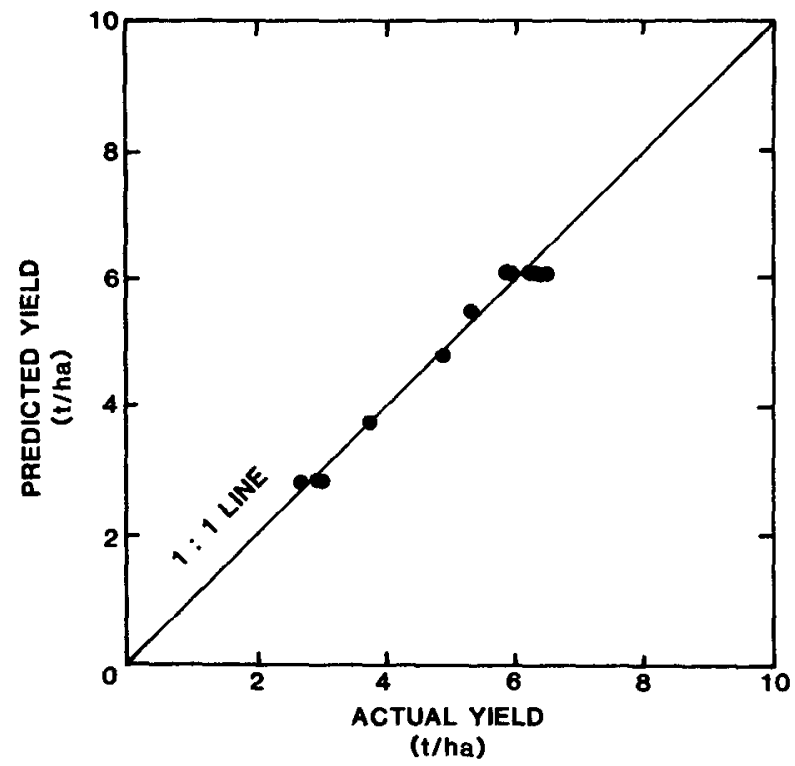

FlG. 3. Simulated versus observed grain yields for winter wheat of the Bridger variety grown with variable amounts of irrigation at Logan, Utah (1979).
TABLE 1. The statistical results for the model when applied at Nephi, UT to dryland winter wheat (1929-49).

\begin{tabular}{lrr}
\hline \hline & 13 & 20 \\
Plowing depth (cm) & 21 & 21 \\
Observations & 0.40 & 0.45 \\
Coefficient of determination & 0.26 & 0.28 \\
Standard error (t/ha) & 0.6 \\
\hline
\end{tabular}

\section{Results and discussion}

The two locations for which predictions were made are Logan and Nephi, Utah. Logan is located in northern Utah while Nephi is centrally located. Both locations have a semiarid climate receiving less than $400 \mathrm{~mm}$ of precipitation annually, and about one third of this amount occurs in the months April through August. July is usually the hottest month. The average high temperature for July at Logan is $31^{\circ} \mathrm{C}$ while Nephi temperatures are generally several degrees higher.

Although the relationship between thermal units and crop growth stage could not be tested extensively, the model performed satisfactorily in yield simulation during these initial tests. The model coefficients given in earlier sections were determined from an optimization procedure used to fit model yields to Nephi actual yields.

An example of model simulated yield plotted against actual yields is given in Fig. 3 for the irrigated trial (Hanks et al., 1980) at Logan for Bridger winter wheat cultivar. In addition to the single season grain yields studied with irrigation from a line source sprinkler, the model was also used to calculate dryland winter wheat yields at the Nephi Agricultural Experiment Farm (Bennett $e t$ al., 1954). Data for the years 1929 through 1949 when winter wheat was grown to test the effect upon yield of cultural practices (tillage, fertilization, etc.) was compared to model output. The results are shown in Table 1.

A summary of the statistical comparison between model predicted and actual grain production is shown in Table 2 for irrigated winter wheat varieties grown at Logan, Utah. The varieties were grown under irrigation water applications $(0$ to $50 \mathrm{~cm}$ ) from a line source sprinkler. A different yield was calculated at each irrigation level from the transpiration as predicted from (4). The empirical coefficients derived for the Nephi data were also used with the Logan data (Hubbard, 1981) with the exception that $A W$ was increased from 0.05 at Nephi to 0.10 at Logan.

TABLE 2. The statistical results for model fit to yield data at Logan, UT (1979).

\begin{tabular}{lccc}
\hline \hline & Bridger & Luke & Nugaines \\
Variety & 12 & 12 & 12 \\
Observations & 0.98 & 0.98 & 0.93 \\
Coefficient of determination & 0.18 & 0.28 & 0.43 \\
Standard error $(\mathrm{t} / \mathrm{ha})$ & \\
\hline
\end{tabular}




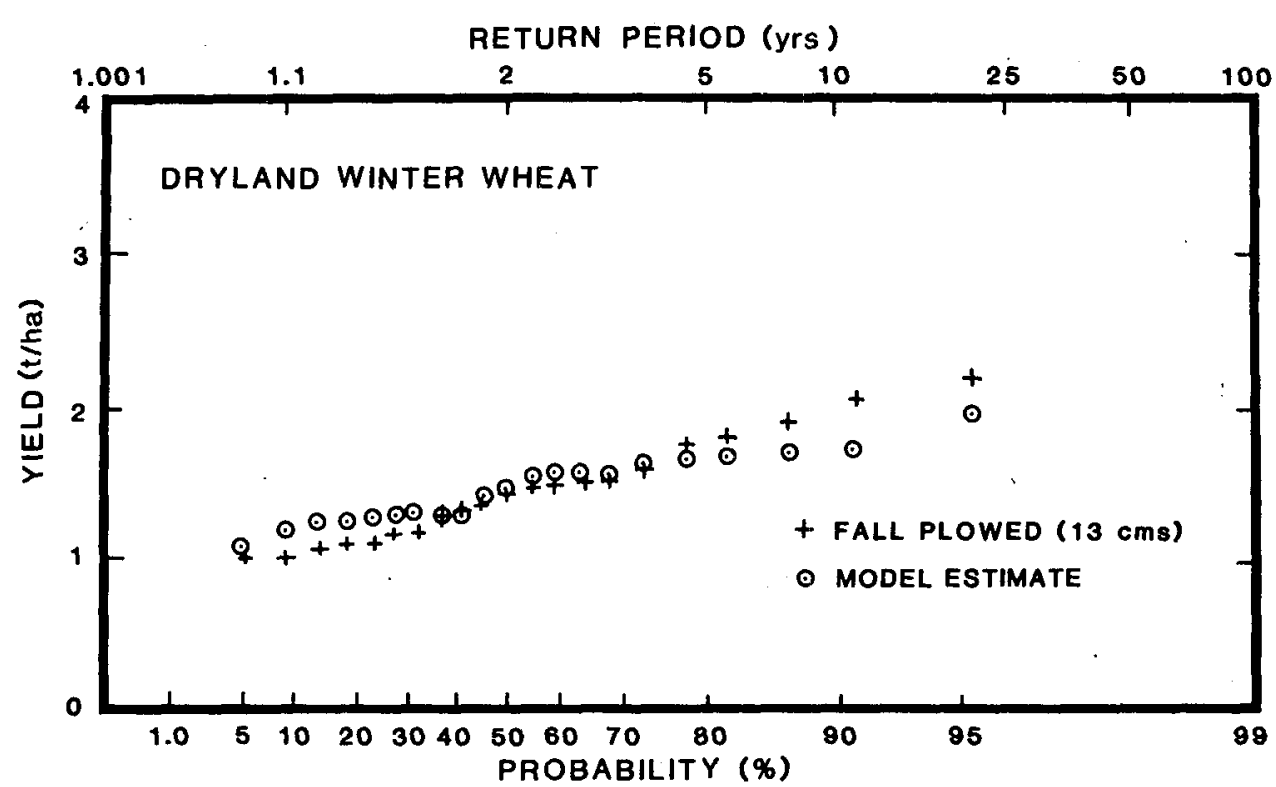

FlG. 4. The probability that a given dry land yield will not be exceeded (plowing depth $13 \mathrm{~cm}$ ) at Nephi, Utah (1929-49).

The ability of the model to predict the historical crop yield distribution at a location is an important consideration. Any model to be used in land use decisions would certainly require this characteristic. The probability of obtaining specific yields at Nephi is shown in Figs. 4 and 5. The distribution as indicated by the model estimates has also been plotted. As can be seen the model simulated yield at Nephi closely estimates the actual yields associated with given return periods.

\section{Summary}

The climate model formulated for this study gave a precise fit to yield data obtained with variable amounts of irrigation water. The same model when used to simulate dryland yields at a single location gave a useful representation of the probability associated with various yields.

Several studies would help to generalize this climate model. For instance, the model should be tested

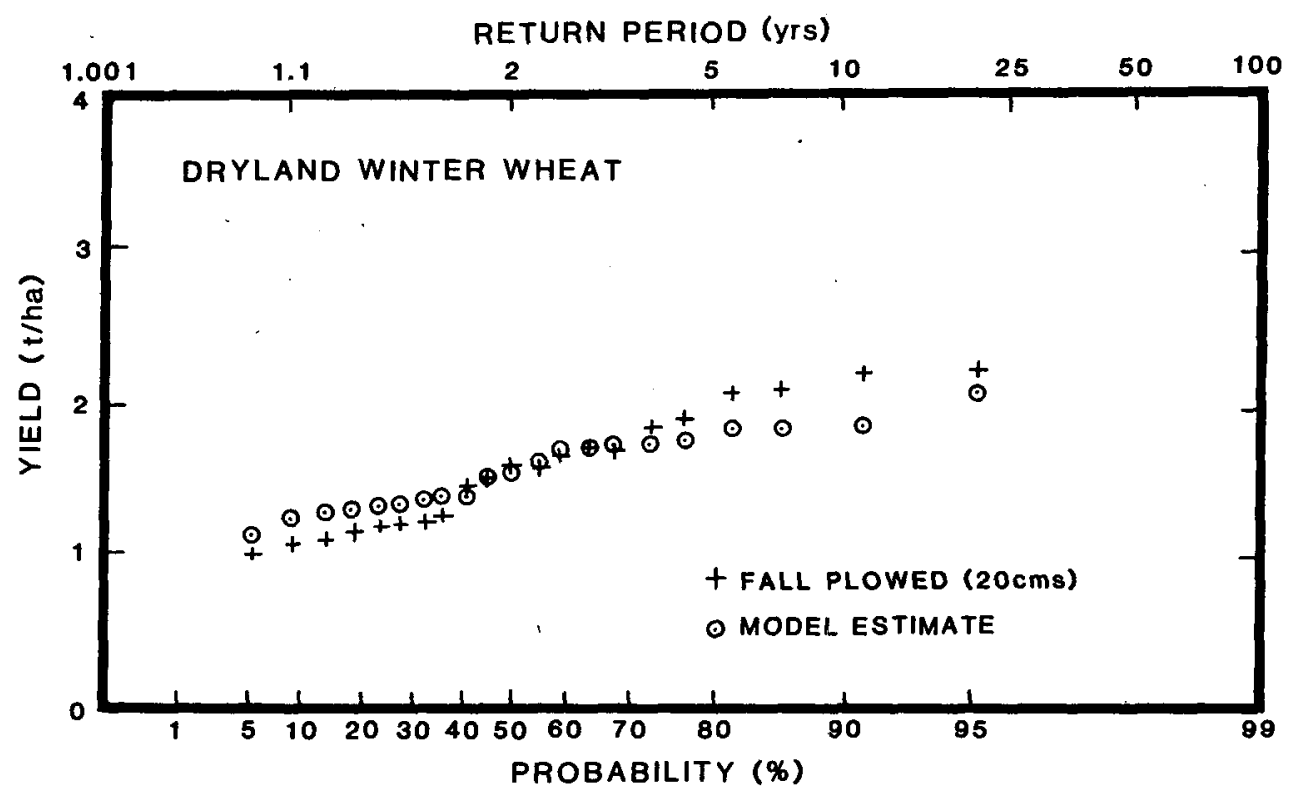

FIG. 5. The probability that a given dry land yield will not be exceeded (plowing depth $20 \mathrm{~cm}$ ) at Nephi, Utah (1929-49). 
with a single variety grown in a number of locations with varying amounts of irrigation water as provided with the line source sprinkler. A similar study using both short and long day cultivars would provide initial data concerning the feasibility of using weighted functions to predict the average yield when several cultivars are widely grown in the same region.

\section{REFERENCES}

Angus, J. F., and M. W. Moncur, 1977: Water stress and phenology in wheat. Aust. J. Agric. Res., 28, 177-181.

Baier, W., 1981: Water balance in crop yield models. Application of Remote Sensing to Agricultural Production Forecasting, A. Berg, Ed., A. A. Balkema, Rotterdam, 272 pp.

Bennett, W. H., D. W. Pittman, D. C. Tingey, D. R. McAllister, H. B. Peterson and I. G. Sampson, 1954: Fifty years of dry land research. Bull. 371, Agricultural Experiment Station, Utah State University, Logan, UT, 81 pp.

Childs, S. C., and R. J. Hanks, 1975: Model of soil salinity effects on crop growth. Soil Sci. Soc. Amer. Proc., 39, 617-622.

Chujo, H., 1966: Differences in vernalization effect in wheat under various temperatures. Proc. Crop Sci. Soc. Japan, 35, 177186.

deWit, C. T., 1958: Transpiration and crop yields. Institute of Biological and Chemical Research on Field Crops and Herbage. Wageningen, Netherlands, $88 \mathrm{pp}$. [Verse-Landbouwk, Order Z. No. 64-6-S Gravenhage.]

Doorenbos, J., and W. O. Pruitt, 1977: Crop water requirements. FAO Irrigation and Drainage paper No. 24, Rome, $144 \mathrm{pp}$.

Ehrler, W. L., S. B. Idso, R. D. Jackson and R. J. Reginato, 1978: Wheat canopy temperatures. Relation to plant water potential. Agron. J., 70, 251-256.

Hanks, R. J., 1974: Model for predicting plant yield as influenced by water use. Agron. J., 65, 660-665.
- D. V. Sisson, R. L. Hurst and K. G. Hubbard, 1980: Statistical analysis of results from irrigation experiments using line-source sprinkler system. Soil Sci. Soc. Amer. J., 44, 886887.

Heuer, G. R., D. F. Heermann, T. B. McKee and J. F. Benci, 1978: Predicting winter wheat phenology using temperature and photo-period. Climatology Rep. No. 70-77, Colorado State University, Fort Collins, 81 pp.

Hodges, T., and P. C. Doraiswamy, 1979: Crop phenology literature reviews for corn, soybean, wheat, barley, sorghum, rice, cotton, and sunflower. NASA Report SR-L9-00409, $82 \mathrm{pp}$.

Hubbard, K. G., 1981: Characterization of winter wheat grain production as influenced by weather, soil, and irrigation factors. Ph.D. dissertation, Department of Soil Science and Biometeorology, Utah State University, Logan, $135 \mathrm{pp}$.

Idso, S. B., R. J. Reginato, J. L. Hatfield, G. K. Walker, J. L. Jackson and P. J. Pinter, 1980; Generalization of the stressdegree day concept of yield prediction to accomodate a diversity of crops. Agric. Meteor., 21, 205-211.

Jolliffe, P. A., and E. B. Tregunna, 1968: Effect of temperature, $\mathrm{CO}_{2}$ concentration and light intensity on oxygen inhibition of photosynthesis in wheat leaves. Plant Physiol, 43, 902906.

Nairize, S., and J. R. Rydzewski, 1977: Effects of dated soil moisture stress on crop yields. Exp. Agric., 13, 51-59.

Nuttonson, M. Y., 1953: Phenology and Thermal Environment as a Means for a Physiological Classification of Wheat Varieties for Predicting Maturity Dates of Wheat. Amer. Inst. Crop Ecol,, Washington, DC, $108 \mathrm{pp}$.

Retta, A., and R. J. Hanks, 1980: Manual for using Model PLANTGRO. Rep. 48, Agricultural Experiment Station, Utah State University, Logan, 21 pp.

Trione, E. J., and R. J. Metzger, 1970: Wheat and barley vernalization in a precise temperature gradient. Crop. Sci., 10, 390392. 